\title{
The effect of shear deformations on the stressed state of the wooden elements of the composite section on inclined metal rods
}

\author{
Vladimir Linkov ${ }^{*}$ \\ Moscow State University of Civil Engineering, Yaroslavskoe shosse, 26, Moscow, 129337, Russia
}

\begin{abstract}
Wooden structures of composite cross-section can be made on flexible links in the form of inclined metal rods (NMS) without the use of glue. The compliance of joints is manifested in the shear deformations of the elements to be joined and reduces the carrying capacity of the composite wooden structures. The article discusses the effect of compliance of NMS-compounds in the form of inclined screwed rods on the stress-strain state of the wooden structures of the composite section. The results of tests for transverse bending of composite wooden elements of natural dimensions are presented. The effect of deformations of mutual shear of joints on deflections on normal stresses in the middle of the span of structures and stresses in inclined screwed rods is considered. It was established experimentally that a linear dependence of the form is observed between shear deformations and other parameters of the stress-strain state of structures $\mathrm{y}=\mathrm{a}^{*} \mathrm{X}+\mathrm{b}$, increase in shear deformation of NMScompound on screwed rods on $1 \mathrm{~mm}$ leads to an increase in deflections, stresses in the construction of a composite section and in inclined rods on $8,39 \mathrm{~mm}, \quad 0,24 \mathrm{MPa}$ и на 20,8 MPa respectively.
\end{abstract}

Improving the efficiency of the use of wood in building structures can be achieved by mastering the manufacture of structures made of solid wood - edged logs, boards, including hardwood - aspen and birch. However, with the maximum possible cross-sectional beam size $150 * 150 \mathrm{~mm}$, it is obvious that the supporting elements of structures made of solid wood can only be composite - of two or three layers, interconnected in a single package with the help of mechanical connections. The connection on the inclined metal rods (NMSconnection) without the use of glue ensures the joint work of the individual branches in the package and refers to the pliable shear connections. The purpose of the work is to assess the effect of the deformability of NMS-joints on the stress-strain state of the wooden structures of the composite section.

The compliance of shear connections is characterized by the mutual shear deformations of the connected elements as a function of the shear force and determines the carrying capacity of the wooden elements of the composite section according to the conditions of the limiting states of the first and second groups. In the works of ARRzhanitsyn / 1, 2, 3 / devoted to the theory of composite rods, the beam design, consisting of individual elements

\footnotetext{
"Corresponding author: nicklinkov@gmail.com
} 
interconnected by flexible shear links, forms a statically indefinable system. One of the main characteristics of such a system are the deformations of malleable bonds obtained from an experiment with structures of natural dimensions. The efficiency of connections is characterized by a stiffness coefficient, which takes into account the deformation of malleable joints. The stiffness coefficient of single-type shear connections in the joining seam is represented, according to / $1,2,3 /$, by

$$
\xi_{\mathrm{i}}=\mathrm{Tc} * \mathrm{~m} / \mathrm{Dc}
$$

The effect of shear deformations on the deflections of a composite wooden element consisting of three layers and having two joints, which are loaded with concentrated forces in the quarters of a span, according to the theory of Rzhanitsyn's composite rods can be represented by:

- on section from the support to the point of application of force, $0 \leq \mathrm{X} \leq \mathrm{a}$, where $\mathrm{M}^{0}=\mathrm{P} \times \mathrm{X}$

$$
W_{1}=\frac{\left[-\frac{P X^{3}}{6}+\frac{8}{9} P \times\left(\frac{X^{3}}{6}-\frac{\operatorname{ch} \lambda_{1}(l-a) \times \operatorname{sh} \lambda_{1} X}{\operatorname{ch} \lambda_{1} l \times \lambda_{1}^{3}}\right)+C_{1} X+C_{2}\right]}{\sum_{i=1}^{3} E_{i} I_{i}}
$$

- on the section from the support to the point of application of force, $\mathrm{a} \leq \mathrm{X} \leq 1$, where $\mathrm{M}^{0}=\mathrm{P} \times \mathrm{a}$

$$
W_{2}=\frac{\left[-\frac{P a X^{2}}{2}+\frac{8}{9} P \times\left(\frac{a X^{2}}{2}+\frac{s h \lambda_{1}(X-a)}{\lambda_{1}^{2}}-\frac{c h \lambda_{1}(l-a) \times \operatorname{sh} \lambda_{1} X}{c h \lambda_{1} l \times \lambda_{1}^{3}}\right)+C_{1} X+C_{2}\right]}{\sum_{i=1}^{3} E_{i} I_{i}}
$$

For compounds on compliant bonds, the indicator of the exhaustion of the carrying capacity is the achievement of the ultimate deformation, the value of which is limited from the condition of the carrying capacity of the component. The actual deformation Dc of the mutual shift of the adjacent bars, as a rule, is obtained from the experiment.

To study the stress-strain state of composite wooden elements with compounds on the NMS, tests of wooden structures were carried out $150 * 450 * 6000$ мм, имеющих составное сечение из трех брусьев $150 * 150 \mathrm{~mm}$, on the basis of joints on the NMS in the form of screwed rods with a diameter of $20 \mathrm{~mm}$ with an enlarged thread pitch and securing the ends of the inclined rods on the wood of the joining elements with the help of washers. The number of NMS was determined from the condition of perception of the total shear on the half-span of the structure, taking into account the design resistance to pulling out the inclined screwed rod $\mathrm{Rv}=1,3 \mathrm{MPa}$. The design of the composite element with connections on the NMS is shown in Figure 1. The tests of the components of natural dimensions were carried out on transverse bending, the load was applied by concentrated forces in the quarters of the span. During the tests, mutual shear deformations were measured at adjacent points of adjacent bars on structural supports, deflections and normal stresses in the middle of the span of the structures, stresses in inclined metal rods. The loading of structures was performed with periodic unloading, which allowed determining not only complete, but elastic and residual components of the measured indicators of the stress-strain state of the structures. Test results are deflections $f$ and normal stresses. $\sigma \mathrm{w}$ in the middle of the span of the structure, the average values of the shear deformations on the supports D and stresses in NMS ost are presented in the graphs in Fig.2 and in Table 1. 

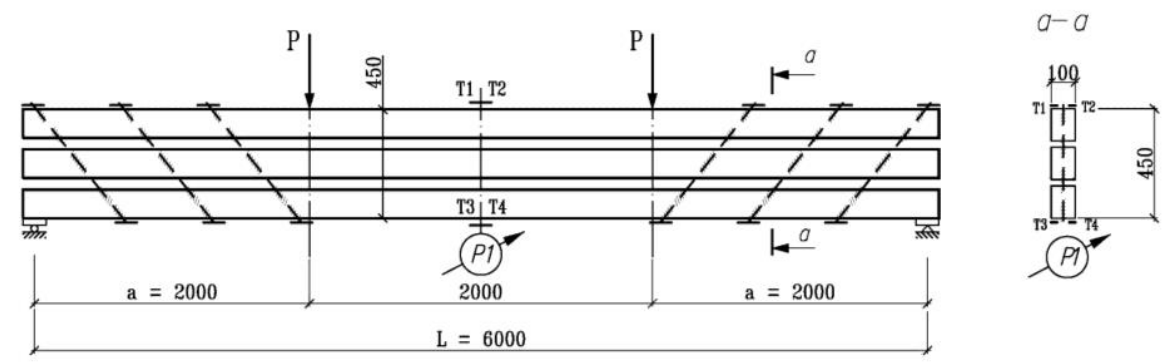

Fig. 1. Construction and loading scheme of a wooden element composite section of long-acting load

Table 1. The results of calculations

\begin{tabular}{|c|c|c|c|c|c|c|}
\hline $\begin{array}{c}\mathbf{N}, \\
\mathbf{k N}\end{array}$ & $\begin{array}{c}\mathbf{M}, \\
\mathbf{k N}\end{array}$ & $\begin{array}{c}\mathbf{T} \\
\mathbf{k N}\end{array}$ & $\begin{array}{c}\mathbf{f}, \\
\mathbf{m m}\end{array}$ & $\begin{array}{c}\mathbf{D}, \\
\mathbf{m m}\end{array}$ & $\begin{array}{c}\boldsymbol{\sigma w}, \\
\mathbf{M P a}\end{array}$ & $\begin{array}{c}\boldsymbol{\sigma s}, \\
\mathbf{M P a}\end{array}$ \\
\hline 0 & 0 & 0,00 & 0 & 0 & 0 & 0,00 \\
\hline 20 & 15 & 44,44 & 8,42 & 0,224 & 3,25 & 12,44 \\
\hline 40 & 30 & 88,89 & 17,26 & 0,775 & 6,25 & 26,85 \\
\hline 60 & 45 & 133,33 & 29,36 & 1,711 & 9,25 & 41,41 \\
\hline 80 & 60 & 177,78 & 43,87 & 2,673 & 12,4 & 56,50 \\
\hline 100 & 75 & 222,22 & 58,75 & 3,670 & 15,6 & 71,88 \\
\hline 120 & 90 & 266,67 & 76,606 & 4,866 & 19,44 & 90,34 \\
\hline
\end{tabular}

From the graphs (Fig. 2.a) it follows that the load corresponding to the upper boundary of the region of elastic work of the structure was NI-II $=110 \mathrm{kN}$, which corresponds to the reliability coefficient KI-II $=112 / 85=1.32>\mathrm{Ktreb}=1.3$. Within the elastic work of the structure, the growth rate of shear deformations $\delta \mathrm{c}$ amounted to $0.016-0.0165 \mathrm{~mm}$ per $1 \mathrm{kN}$ change in shear force. Graphs of shear deformations show that when the structure is loaded up to $40 \mathrm{kN}$, when the shear force on the half-span of the structure was Tsdv $=88.9 \mathrm{kN}$, the connection transmitted the force between the rod and the connected elements mainly due to the adhesion of wood with the threads of the inclined screwed rods. When the load on the structure is $\mathrm{N}=40 \mathrm{kN}$, the shearing force per one inclined rod was 0.6 of its calculated bearing capacity due to the pull-out condition, with a design pull-out resistance of $1.3 \mathrm{MPa}$ and a working area of the rod 20000 sq. Mm. When the load on the structure is $60 \mathrm{kN}$, the shearing force per 1 rod was 1.2 of its calculated bearing capacity due to the pull-out condition. Consequently, with the load on the structure between $40 \mathrm{kN}$ and $50 \mathrm{kN}$, the joint operation changed and the transfer of force between the rod and wood began to be carried out not only through the thread, but also through washers, which entered into the work due to the connection flexibility on the inclined screwed rods. The magnitude and nature of the distribution of stresses in inclined rods shows that under load, corresponding to the calculated bearing capacity of the structure $\mathrm{N} \Pi=85 \mathrm{kN}$, all compliant connections in the form of inclined screwed rods with a diameter of $20 \mathrm{~mm}$ and additional fastening of the ends by washers are included in the work of the composite bending element this shearing force in each joint seam is distributed between the inclined screwed rods evenly. The proportion of shear deformations of residual Do and elastic Dy in the composition of total shear deformations Dsdv was $48 \%$ and $52 \%$, respectively, for the design load $\mathrm{Np}=85 \mathrm{kN}$, 
respectively. With the inclusion of washers installed at the ends of the inclined rods, the proportion of elastic deformations increased to $62 \%$.
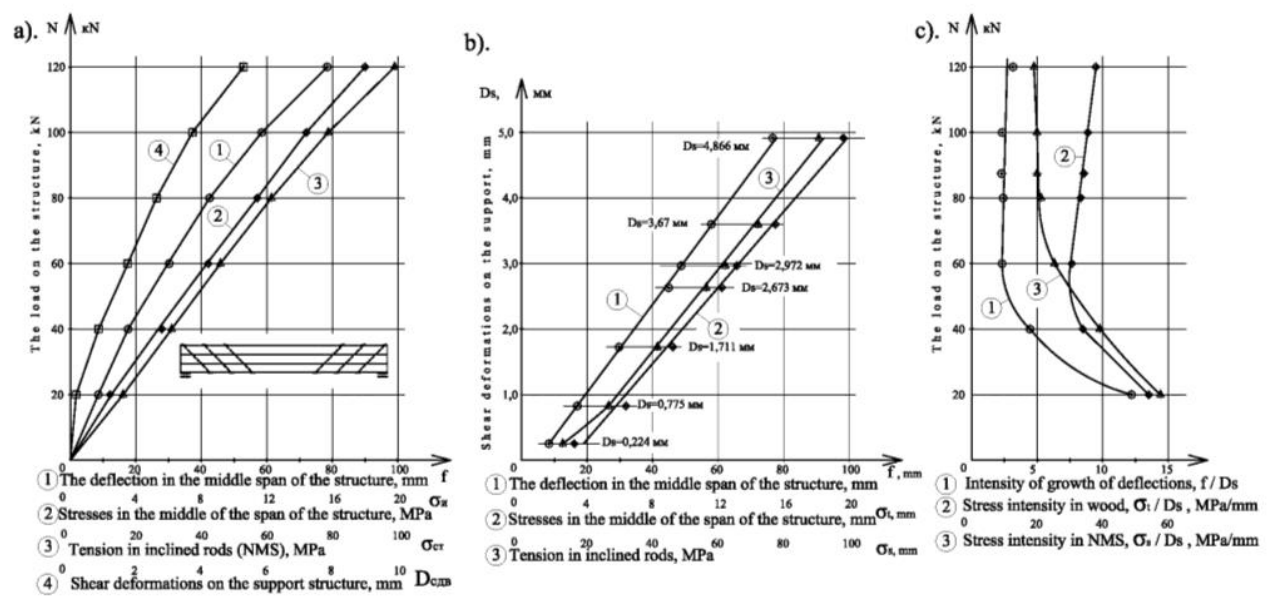

Fig. 2. The test results of the wooden element of the composite section of full-scale dimensions

Since the compliance of joints determines the performance of structures with a composite section, we consider the dependencies of the basic parameters of the stress-strain state of structures - normal stresses, mid-span deflections, stresses in inclined rods - on shear deformations for NMS connections on screwed rods with washers. The actual dependencies between the indicated values are presented in Fig. 2.b. From the consideration of the graphs, we see that at all loading steps a linear dependence is observed $\mathrm{Y}=\mathrm{a} * \mathrm{X}+\mathrm{b}$ between shear deformations and other parameters of the stress-strain state. For the independent variable, the mutual shift deformations of the connected elements $\delta \mathrm{c}$ were taken and the equations of connection between the experimental values were obtained in the form of first-degree polynomials, the coefficients and free terms for which were determined by the least squares method:

- mid-span deflections $\mathrm{f}=15,27 * \delta \mathrm{c}+3,49$;

- mid-span normal stresses $\sigma=3,23 * \delta \mathrm{c}+3,747$;

- stresses in an inclined screwed in $\operatorname{rod} \sigma \mathrm{NMS}=15,56 * \delta \mathrm{c}+14,79$.

Determining the calculated values of deflections $f$ and normal stresses $\sigma$ for a solid section design, we calculate the increment of the indicators of the stress-strain state of the structure due to the compliance of shear ties: deflections fcomp $=\mathrm{f}-\mathrm{ff}$, normal stresses $\sigma c o m p=\sigma-\sigma$, as well as determine the growth rate of deflections and stresses in the structure with increasing shear deformations as a ratio for deflections fcomp/Ds, for normal stresses $\sigma c o m p / D s$ and for stresses in rods of NMS connections $\sigma \mathrm{s} / \mathrm{Ds}$. The results of the calculations are presented in the graphs in Fig. 2.in and in table. 2

Table 2. Intensity of growth of deflections and stresses in the construction of a composite section with deformations.

\begin{tabular}{|c|c|c|c|c|c|c|c|}
\hline \multirow{2}{*}{$\begin{array}{l}\mathbf{N}, \\
\text { KN }\end{array}$} & \multirow{2}{*}{$\begin{array}{c}\text { f full, } \\
\text { mm }\end{array}$} & \multirow{2}{*}{$\begin{array}{c}\sigma \\
\mathrm{MPa}\end{array}$} & \multirow{2}{*}{$\begin{array}{c}\mathbf{f} \operatorname{comp}= \\
\mathbf{f}-\mathbf{f} \\
\text { full, } \\
\mathbf{M M}\end{array}$} & \multirow{2}{*}{$\begin{array}{c}\text { ocomp }= \\
\sigma-\text { ofull, } \\
\mathrm{MPa}\end{array}$} & \multirow{2}{*}{$\begin{array}{c}\text { f comp } \\
\text { Ds }\end{array}$} & $\begin{array}{c}\text { Ocomp } \\
\text { Ds }\end{array}$ & $\begin{array}{l}\text { Os } \\
\text { Ds }\end{array}$ \\
\hline & & & & & & $\mathrm{MPa} / \mathbf{m m}$ & $\mathrm{MPa} / \mathrm{mm}$ \\
\hline 0 & 0,00 & 0,00 & 0,00 & 0 & 0 & 0 & 0 \\
\hline 20 & 5,43 & 2,96 & 2,99 & 0,29 & 13,34 & 1,28 & 55,55 \\
\hline 40 & 10,86 & 5,93 & 6,40 & 0,32 & 8,25 & 0,42 & 34,65 \\
\hline
\end{tabular}




\begin{tabular}{|c|c|c|c|c|c|c|c|}
\hline 60 & 16,30 & 8,89 & 13,06 & 0,36 & 7,64 & 0,21 & 24,20 \\
\hline 80 & 21,73 & 11,85 & 22,14 & 0,55 & 8,28 & 0,21 & 21,14 \\
\hline 100 & 27,16 & 14,81 & 31,59 & 0,79 & 8,61 & 0,21 & 19,59 \\
\hline 120 & 32,59 & 17,78 & 44,01 & 1,66 & 9,04 & 0,34 & 18,56 \\
\hline & & & & Middle & 8,39 & 0,24 & 20,81 \\
\hline
\end{tabular}

From consideration of the graphs and Table 2, we see that with a load on structures above $0.5 \mathrm{~Np}=43 \mathrm{kN}$, an increase in shear deformations Dsdv by $1 \mathrm{~mm}$ leads to an average increase in mid-span deflection by $8.39 \mathrm{~mm}$, and normal mid-span stress by 0,24 MPa, stresses in inclined rods of NMS-joints at $20.8 \mathrm{MPa}$.

Based on the above, the following conclusions were made.

1. Wooden elements of composite section with flexible shear ties in the form of inclined screwed rods with washers at the ends have sufficient bearing capacity according to the conditions of the first limiting state. With a load of $\mathrm{N}_{\Pi}=85 \mathrm{kN}$, corresponding to the design bearing capacity of the structure, the mid-span normal stresses were $\sigma \mathrm{W}=13.36$ $\mathrm{MPa}$, which does not exceed the calculated bending resistance for pine wood of the 2 nd grade $\mathrm{R}=14-15 \mathrm{MPa}$. The reserve capacity was from $4 \%$ to $11 \%$.

2. Designs have sufficient bearing capacity under the conditions of the second limit state. With a load of $\mathrm{N}_{\Pi}=60 \mathrm{kN}$, corresponding to the bearing capacity of the structure for regulatory loads, mid-span deflections were $\mathrm{f}=29.4 \mathrm{MPa}$, which does not exceed the ultimate deflection of the aesthetic-psychological requirements $\mathrm{fu}=1 / 200 \mathrm{~L}=30 \mathrm{~mm}$.

3. The load corresponding to the upper boundary of the region of elastic work of the structure was NI-II $=110 \mathrm{kN}$, which corresponds to the reliability coefficient $\mathrm{K} \mathrm{I}-\mathrm{II}=$ $110 / 85=1.32>$ Kneed $=1.3$ and confirms the performance of the NMS-compounds in composite structures full size.

4. Experimentally established functional dependences between shear deformations of NMS connections in the form of screwed rods with washers and the main parameters of the stress-strain state of full-sized structures - deflections, normal stresses in the middle of the span of the structure and in inclined rods. It is established that an increase in shear deformation of the NMC-compound by $1 \mathrm{~mm}$ leads to an increase in deflections, stresses in the structure and in inclined rods by $8.39 \mathrm{~mm}, 0.24 \mathrm{MPa}$ and $20.8 \mathrm{MPa}$, respectively.

\section{References}

1. Rzhanitsyn A. Composite rods and plates. Stroiizdat (1986)

2. Rzhanitsyn A. Composite rods and plates. Stroiizdat (1948)

3. Rzhanitsyn A. Fundamentals of the theory of calculation of composite rods. MISI (1977)

4. Linkov V. Structures on the basis of wooden elements of composite section with connections on inclined metal rods without the use of glue. - Industrial and civil engineering. 11, 29-31 (2012)

5. Linkov V. Modeling the operation of wooden beams of composite cross section on flexible links using the theory of composite rods A.R. Rzhanitsyna. CMSC 5, 30-35 (2011)

6. Popov E., Filippov V. The effect of stiffness of shear connections when calculating ribbed panels on a wooden frame. Forest Journal. 4, 136-146 (2016)

7. Makarov G., Frolov A. Connections of elements of wooden structures with the use of steel rods (pins) and their fire resistance. MARCHI, 384-386 (2015) 
8. V. Linkov. Connections on inclined screwed rods in wooden beams for the reconstruction of buildings of the textile industry. Textile Technology. 3 (369). 212-217 (2017)

9. Zhadanov V., Arkaev M. Studies of wooden beams reinforced with twisted cruciform rods. Industrial and civil engineering. 11 , 5-11 (2017)

10. Klyukin A., Pyatikrestovsky K. Cover-shell with edges made of solid wood elements of composite section. Bulletin of the Irkutsk State Technical University. 1, $103-106$ (2015)

11. Series Type solutions for built-up timber beams with semi-rigid connections.Proceedings of the Institution of Civil Engineers.707-719 (1980)

12. Walford G. Bryan. Tests on nailed and glued timber cylindrical shells. ASCE. 106. 247263 (1980)

13. E. George Stern. Nailed Flitch beams and griders providing opportunities in wood construction. Virginia Polytechnic Instititute\& State University Department. 55-64 (1982)

14. Hugo, Francois de V. Wooden beams joined with steel plates. ASCE 103. 1005-1014 (1977) 